\title{
Evaluation of Numerical Methods to Model Structural Adhesive Response and Failure in Tension and Shear Loading
}

\author{
Luis F. Trimiño ${ }^{1} \cdot$ Duane S. Cronin $^{1}$
}

Received: 30 October 2015/Accepted: 13 January 2016/Published online: 1 February 2016

(C) Society for Experimental Mechanics, Inc 2016

\begin{abstract}
Improved energy efficiency in transportation systems can be achieved with multi-material lightweight structures; however, joining often requires the use of adhesive bonding and design efforts are challenged by the paucity of data required to represent adhesives in numerical models. The data for three epoxy structural adhesives tested in tension and shear over a range of strain rates $\left(0.001-1000 \mathrm{~s}^{-1}\right)$ is reported. The range of experimentation addresses regular operation and extreme conditions (crash scenarios) for vehicles. The data was implemented with cohesive and solid elements; and the models were assessed on their ability to reproduce adhesive material response. Good agreement was achieved using both approaches. In average the coefficients of determination $\left(\mathrm{r}^{2}\right)$ between measured experimental response and simulations were 0.81 for tension and 0.59 for shear, with $2 \%$ difference in the prediction of stress at failure. The cohesive formulation was computationally efficient and reproduced rate effects, but was limited in representing the response of the non-toughened epoxy. The solid element formulation required longer simulation times, but yielded similar accuracy for tension ( $2 \%$ difference in stress to failure and $r^{2}$ values of 0.98 , on average). However, the shear response accuracy $\left(r^{2}=0.53\right)$ was reduced by
\end{abstract}

Electronic supplementary material The online version of this article (doi:10.1007/s40870-016-0045-7) contains supplementary material, which is available to authorized users.

Luis F. Trimiño

ltrimino@uwaterloo.ca

Duane S. Cronin

dscronin@uwaterloo.ca

1 Department of Mechanical and Mechatronics Engineering, University of Waterloo, 200 University Avenue West, Waterloo, ON N2L 3G1, Canada coupling between shear and tension strain rate effects. Numerical simulation of structural adhesives requires constitutive models capable of incorporating uncoupled deformation rate effects on strength. The results of this study indicate that a cohesive model can provide adequate representation of an adhesive joint for tensile and shear loading across a range of deformation rates.

Keywords Structural adhesives - Deformation rate effects - Toughened structural epoxy - Explicit finite element model $\cdot$ Cohesive element

\section{Introduction and Background}

Increasing requirements for improved energy efficiency in transportation systems have led to the introduction of lightweight materials and multi-material structures. These structures have been enabled by the use of adhesives for joining. Traditional joining methods such as fasteners or welding restrict the use of dissimilar materials and/or thin gage components that are key to producing light weight structures $[1,2]$.The adoption of adhesive joining not only reduces the overall weight of the structure [3]; but also provides joints that are continuous and therefore stronger with reduced stress concentrations [3]. Although joining with structural adhesives is currently in use by some automobile manufacturers [2, 4] and bonded structures have been tested under operational conditions [5-9]; a major obstacle to incorporating adhesive joints in designs is the lack of appropriate data to characterize and represent adhesive joints in numerical models and simulations to support computer aided engineering (CAE) [10]. Incorporation of adhesive joints in numerical models can be undertaken with relatively simple implementations using 
tied nodes between the adherends and a critical stress criterion, to more comprehensive cohesive element and solid element constitutive models. All of these representations vary in complexity and the amount of data required for implementation, with corresponding requirements for mechanical testing. The required properties can range from simple strength values to full traction-separation curves, and the incorporation of deformation rate effects. Typically, strain-stress curves for tension, compression and shear at different strain rates; values for fracture toughness in Modes I and II, traction-separation behavior, damage response and strain to failure are required. Mechanical properties in adhesives are generally measured using bonded joints subjected to uniaxial tension, or peal [11] or by using thin lap shear tests [12].

Measuring the mechanical properties of adhesives can be undertaken using many different methods; a search of the ASTM standards [13] for the mechanical testing of adhesives identified 517 documents pertaining to testing, out of which 94 are different active standards. These standards include 15 different test protocols for adhesion, 24 for tension; 8 for compression; and 15 different tests for shear. Generally, these tests require the preparation of a bonded specimen and subsequent testing in order to measure the desired mechanical property. Unfortunately, many of the configurations produce results that are influenced by the adherend material stiffness, strength, and joint geometries [14] resulting in stress concentrations and complex modes of loading [15] affecting the measured properties [16]. The variability in measured results can be observed in published data for adhesive testing using lap-shear and T-peel test $[17,18]$.

Untoughened epoxy adhesives typically exhibit relatively high strength at failure $(\geq 70 \mathrm{MPa})$, low strain to failure $(\leq 0.1)$ [19] and low fracture toughness $\left(\sim 0.4 \mathrm{~J} \mathrm{~m}^{-2}\right)[20$ $25]$. Toughened epoxy formulations incorporate a second toughening phase, typically butadiene or other polymer (EPM, ABS, polyolefins) [21, 26, 27], and demonstrate increased ductility $(\geq 0.1 \mathrm{~mm} / \mathrm{mm}$ at failure) and fracture toughness $\left(\geq 1.5 \mathrm{~J} \mathrm{~m}^{-2}\right)$. This type of adhesive is ideal for applications where the bonded joints are required to maintain integrity under high deformation, which is generally the case in crashworthiness scenarios for transportation systems. Crashworthiness and other load case scenarios result in a range of deformation rates, and under such conditions, it is important to consider strain rates effects in the constitutive model. In particular for adhesives, the literature reports changes in the mechanical response; typically increase in the stress to failure and decrease in the strain to failure [10, 2833 , and in some cases changes in modulus of elasticity. Conflicting information is reported for fracture toughness. In certain cases, increases with strain rate have been reported [34, $35]$ while others have found that there are no noticeable changes [25], and still others report decreases with increasing strain rate [36-38]. Many different constitutive models can be used for modeling adhesives, ranging from simple elastic models, metals plasticity models, and viscoelastic models [39-41]. Failure is often incorporated using a critical stress or fracture toughness criterion. Three common numerical implementations include: simple tied nodes with a critical stress failure criterion or crack opening displacement approach to predict failure, cohesive element formulations incorporating traction separation curves and material toughness, and solid continuum element formulations. Simple implementations involving tied nodes, although numerically efficient and requiring very little information for implementation are known to be problematic due to numerical instabilities (often termed unzipping). Although the incorporation of a damage criterion can mitigate this issue, deformation rate effects are generally not considered in this approach. Further, this approach can misrepresent the joint stiffness, which is determined from the adherend materials and not from the adhesive itself. In recent years [42, 43], advances in cohesive element formulations have incorporated traction-displacement curves to provide a better description of the material response to load and fracture mechanics concepts to predict failure. Cohesive elements allow for progressive failure in ductile adhesive materials, avoiding the numerical instabilities that are generally observed with tied nodes. In addition to incorporating Mode I (pure tension), Mode II (pure shear) and mixed-mode response, recent cohesive formulations [43, 44] include strain rate effects and are numerically efficient. Discretization using solid continuum elements and an appropriate constitutive model is considered to be the most accurate representation of an adhesive joint, if the finite element size is sufficiently small. This approach can require a large number of elements, making it computationally expensive. Constitutive models for use with solid elements include: elastic with failure, metals plasticity models, plasticity models with strain rate effects, viscoelasticity and continuum damage models. In general, these models require a relatively large set of material properties and data to accurately represent the adhesive joint. Limitations include a lack of accounting for rate effects, material asymmetry and prediction of failure. For example, an elastic model with failure can predict the elastic response of the material but fails to describe material damage. Metals plasticity models can incorporate strain rate effects and damage, but often rely on von Mises or other yield criteria applicable to metals to link the tensile response to the compression or shear response, which can be inaccurate for many polymeric materials. Although traditional viscoelastic models account for deformation rate effects, most do not incorporate a description of material damage and failure. Some constitutive models, such as the Semi-Analytical Model for Polymers (SAMP-1) [45] have been developed specifically for polymers, incorporating tension, shear and compression behavior separately, along with deformation rate effects. 
Modeling of structural adhesives is widely discussed in the literature [39-41, 46-48]. Simple representations starting with the use of beam elements to represent the substrate coupled with iso-parametric elements to represent the adhesive was successfully implemented by $\mathrm{Wu}$ [49] to generate the stress distribution of different type of joints. Van Hoof [50] used tied nodes between surfaces to represent adhesive joints in the analysis of delamination in composite materials. These simplified methods can be useful to get insight into general behavior in joints under load and in some cases provide stress distributions, but prediction capabilities are constrained due to the limited information that these models require (i.e. stresses to failure). For example, behaviors that depend on the true stiffness in the joint can be biased since the stiffness of a simple tied contact is generally assumed in the implementation [51] and is arbitrarily independent of the true stiffness of the adhesive itself. In contrast, highly sophisticated user defined materials have been used successfully to describe bulk material behavior under linear elastic conditions, strain softening or strain hardening effects, and to predict the effects of strain rate dependency or the effects of damage in the unloading phase [47, 52, 53]. Although these models can be highly accurate, they require the use of element formulations with refined meshes that are computationally expensive; calculation times can be prohibitive and impractical, e.g. analysis of a complete vehicle [7]. Cohesive elements have been used successfully to accurately describe joint load response and predict crack propagation of bonded joints in Mode I load conditions [5456] and in mixed mode loading scenarios [23]. Even though limitations in regards to rate dependencies have been partially addressed [34, 42-44], other limitations in cohesive formulations, as identified by Needleman [57] include size effects, and the dependence of material parameters on deformation rate. Success in modeling structural adhesives is not only limited to the reproduction of experimental coupons; but also at the structural level [7, 58-60] under quasistatic and impact loads with good agreement for predicted loads, deformation patterns and modes of failure between simulations and experiments. The techniques have also been used in the analysis of complex joints such as the interface between welds and adhesive materials in hybrid joints [61]. Regardless of the numerical implementation used for the analysis of a bonded joint or a bonded structure, the analysis using numerical methods is not possible without mechanical properties that can describe the adhesive material response. The minimal requirements being the uniaxial tension response or/and pure shear data.

In this study, the mechanical properties of three structural epoxy adhesives (DP-460NS, SA-9850 and EC-2114, 3M Limited, Canada) were measured. The testing was undertaken using bulk material at different strain rates under tension (0.0001-1000 $\mathrm{s}^{-1}$ ) and using thick adherend lap shear samples $\left(0.005-50 \mathrm{~s}^{-1}\right)$ to measure the shear properties. This study aims to provide much required mechanical data and an understanding of available numerical implementations for modeling structural adhesive response and failure that can be used in the analysis of bonded structures.

\section{Methods}

\section{Materials}

Three commercial structural adhesives were investigated, a traditional non-toughened epoxy, and two toughened epoxies. The non-toughened material was a single part epoxy (EC-2214, 3M Limited Canada) [17, 62] with a small percentage of a synthetic elastomer (1-5\% per weight). The material was cure for an hour at $120^{\circ} \mathrm{C}$. This adhesive was designed to bond metals and high temperature plastics. The second adhesive was a two-part structural epoxy base in a phenolic resin and modified with acrylonitrile butadiene (CTNB) for enhanced strength (7-13\% per weight) (DP-460NS, 3M Limited, Canada) [18, 63]. The manufacturer data sheet shows that best performance is obtained with a curing cycle of $2 \mathrm{~h}$ at $70{ }^{\circ} \mathrm{C}$. The last material (SA-9850, 3M Limited Canada) [64] was described by the manufacturer as one part impact resistant adhesive formulated for bonding contaminated or unprepared steel and aluminum materials. From the data sheet a curing cycle of $1 \mathrm{~h}$ at $170{ }^{\circ} \mathrm{C}$ was selected. The materials considered, permit to compare a typical epoxy adhesive (EC-2214), an adhesive with enhanced toughness (DP$460 \mathrm{NS}$ ) and one that was specifically designed for impact resistance (SA-9850).

\section{Tensile Testing}

Specimens were extracted from cast adhesive sheets $3 \mathrm{~mm}$ in thickness by machining. The coupon geometry has been used previously for high deformation rate tensile testing [65] and was used for the current study so that the same sample geometry could be used over a wide range of deformation rates and maximized the number of samples that could be machined from the cast material [66]. This specimen geometry has been compared to the ASTM type $\mathrm{V}$ sample and has provided similar results for metals [65, 67]. To ensure that this geometry would not introduce artifacts, results of coupon tensile testing at low strain rates were compared with the ASTM type V geometry [66] for the uniaxial testing of polymers. It was found that the critical values (stiffness, yield strength, strain to failure) were in good agreement for both test geometries.

Materials were tested at quasi-static strain rates (0.001-0.7 $\mathrm{s}^{-1}$ ) using a hydraulic test frame (Instron, 
Fig. 1 Experimental set-up a Quasi-static, b intermediate range and $\mathbf{c}$ high strain rate

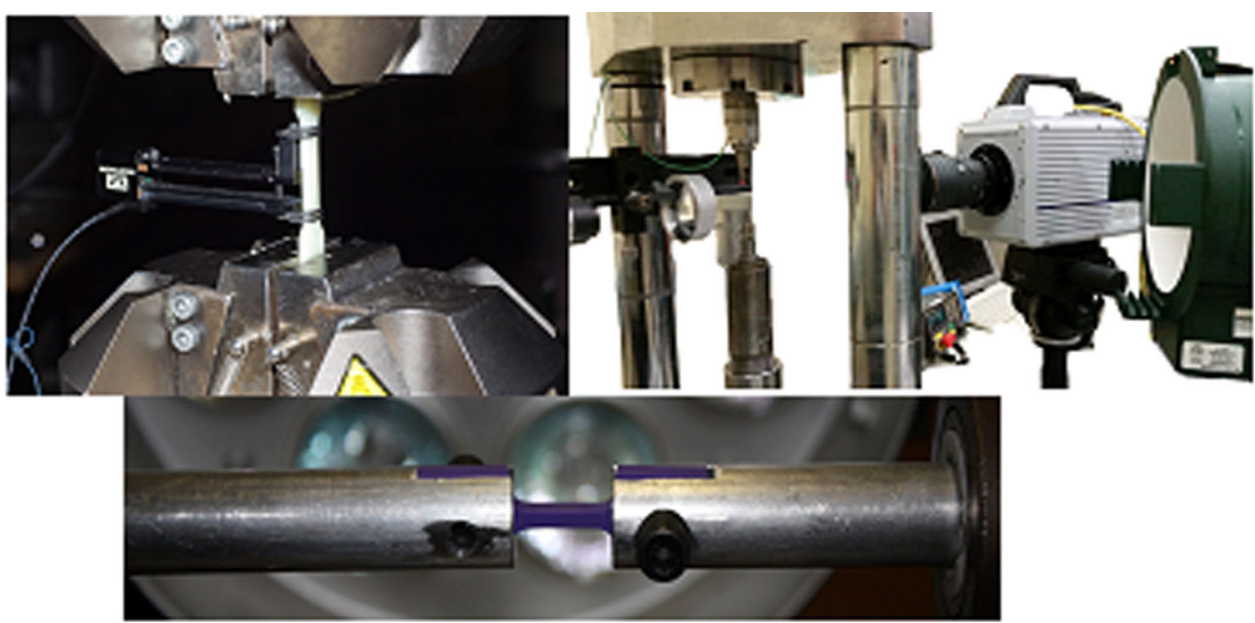

Model 1331) in conjunction with a dynamic extensometer (Instron, Model 2620-601) and a load cell (Strain Sert, model FL25U-2DG). At the intermediate strain rates $\left(10-100 \mathrm{~s}^{-1}\right)$, a hydraulic frame equipped with a quartz piezoelectric load cell (Kistler model 9321B) and charge amplifier (Kistler type 5010B) was used to measure force. Digital image correlation (DIC) [68] was used to measure specimen deformation (VIC-2D [69]) with images captured using a high speed camera (Photron Fastcam SA-4) and LED light source (AADYN Technologies, Jab Bullet model). At high strain rates, $1000 \mathrm{~s}^{-1}$ or higher, a tensile split Hopkinson pressure bar was used (Fig. 1). All testing was conducted at room temperature.

\section{Shear Testing}

The adhesive shear properties were measured using thick lap shear specimens (TLS), based on the ASTM D5656 standard [70]. The samples were constructed by bonding two $3 \mathrm{~mm}$ thick steel substrates (SAE $1018 \mathrm{HR}$ ) $16 \mathrm{~mm}$ in width and $25.53 \mathrm{~mm}$ in length. The two pieces overlap by $5.8 \mathrm{~mm}$ to create a $1 \mathrm{~mm}$ thick adhesive joint and a fixture was used to maintain the geometrical dimensions of the bond during the curing process. The specimens were used to obtain the shear response of the adhesive; since the adherends were quite rigid compared to the adhesive, it was assumed that the results correspond to those of the bulk material since cohesive failure was present during the test.

The coupons were tested over strain rates ranging from 0.005 up to $50 \mathrm{~s}^{-1}$; and were performed using a hydraulic test frame in conjunction with a load cell (Transducer Techniques, model SWP-20K) and a Linear Variable Differential Transformer (LVDT) (Omega, type LD-320-7.5) mounted on the sample to measure displacement. Custom offset grips were used to maintain the alignment of the sample with the applied load and minimize the introduction of bending moments during the test. Imaging of the test and post-test sample analysis confirmed that there were no misalignments and that the setup did not introduce any measurable bending in the test sample.

\section{Adhesive Modeling and CAE Implementation}

The ability to model the mechanical response and failure of adhesive joints is essential for integration into the design process. One challenge in modeling adhesive joints is the small thickness of the adhesive bond, resulting in relatively small elements. For example, vehicles and substructures are often modeled with elements on the order of 3-5 $\mathrm{mm}$ in dimension; whereas a typical bond thickness may be $0.15 \mathrm{~mm}$ leading to a significant reduction in time step and increased computational cost for solid continuum elements. A second challenge is the level of detail in the material or constitutive model, which determines the mechanical properties that must be measured as inputs to the model. To address the large number of combinations possible, three approaches in order of increasing complexity and computational cost were identified for investigation in this study: tied nodes, a cohesive zone model, and a continuum model.

A computationally efficient approach to modeling adhesive joints is a simple tied interface, where nodes on adjacent adherends are tied to one another and failure is predicted through the use of a stress-based criterion [39, 71, 72]. Although this method is very computationally efficient and some implementations include apparent ductility of the adhesive through a prescribed displacement corresponding to fully damaged material, this method does not incorporate the actual bond thickness or adhesive elastic response, and can be prone to numerical instability [50]. Further, available implementations in a commercial explicit finite element code (LS-Dyna, LSTC) did not include deformation rate effects, bond thickness, or the compliance of the adhesive. Initial studies identified these 
aspects as significant limitations and this formulation was not pursued further.

Cohesive zone models (CZM) provide a computationally efficient, albeit incomplete, formulation to represent two important modes of loading on an adhesive joint: tension and shear. Further, the adhesive bond thickness is included as is the compliance of the adhesive. In this study, a cohesive element formulation incorporating tensile, shear, fracture and damage properties was investigated [43]. Importantly, this implementation also included deformation rate effects and an interpolation to consider mixed-mode loading. The measured parameters included the tensile traction displacement curve, the shear traction displacement curve, Mode I fracture toughness, and deformation rate effects in tension characterized by an increase in material strength with increasing deformation rate. The Mode II fracture toughness was not directly measured and was determined from the shear tests as described in the methods section.

Continuum approaches incorporating solid elements have been used to investigate stress gradients in a joint and can aid the design engineer to understand the adhesive performance in a particular joint configuration $[48,58]$, but are not often used for large structures due to the high computational cost. Specifically, multiple elements are required through the small thickness of the adhesive leading to a large number of elements and increased solution time for a given model. A continuum approach requires a constitutive model to describe the material response, often providing stress as a function of strain history and strain rate. There are a large number of material models that may be considered, and the use of a particular model is dictated by the sensitivity of a material to deformation rate, damage and mode of loading. Classes of materials investigated included: elastic, viscoelastic, viscoplastic, metals plasticity, and polymer-specific models. In general, the experimental test results determined that the constitutive model was required to incorporate elastic response, damage or plastic response, deformation rate effects, asymmetry in tension and compression, and shear response. Although many different models exist with some or all of these aspects, noted limitations included incorporation of deformation rate effects, the asymmetric yield surface [73], and the general ability to fit the wide range of data available from the experimental tests. Following investigation of several different models, the Semi-Analytical model for Polymers (SAMP-1) constitutive model developed by Kolling et. al [45] and implemented in a commercial finite element solver (LS-DYNA) [74] code was identified for use in the current study. The SAMP-1 model incorporates specific stress-strain curves for different modes of loading (tension, shear, and compression) and incorporates strain rate effects.

\section{Implementation of Experimental Test Data in Constitutive Models}

Multiple tests were undertaken for each mode of loading and deformation rate; the experimental data was used in whole or in part as required to implement the various constitutive models used in this study. In the case of the cohesive element, the models required strength data as a function of strain rate, this information was extracted from the experimental test data by cross-referencing stress at failure against strain rate. The strain rate effects were described with the use of a log-linear model. Mode I fracture toughness was measured by the manufacturer using the tapered double cantilever beam tests [75] and the average values from the measurements [64] were used in the cohesive constitutive model. Mode II data was first approximated using an expression (Eq. 1) that relates the maximum shear strength $(\tau)$ with the displacement at failure $\left(\mathrm{d}_{\mathrm{fail}}\right)$, the area under the normalized shear stressstrain curve $\left(\mathrm{A}_{\mathrm{TSC}}\right)$ and the energy release rate [67]. In the case where no shear data is available, the value of Mode II energy release can be approximated as $2-10$ times the Mode I value [76, 77]. In cases where the initial Mode II approximation (Eq. 1) did not predict the material strain to failure accurately; the value was recalculated using an inverse method. The method consisted in varying the Mode II value until the response of a single element in pure shear at the lowest strain rate followed that of the experimental data and there were no differences in strain to failure. Cohesive elements require a curve to describe the traction separation response in the material, the literature $[55,78$ 80] suggest the use of bilinear or bilinear with plateau curves; although some authors have claimed that the shape does not have a significant effect on the response [55]. The traction separation curve was determined by normalizing the shear response at the lowest strain rate. The normalization process consisted of dividing the measured curve by the maximum measured stress and strain values respectively in each axis to obtain the normalized traction-displacement curve.

In the case of the implemented solid formulation and constitutive model (SAMP-1) the model required true stress as a function of plastic strain to define the material response for tension and shear. For the tensile tests, the measured experimental stress-strain data for each specimen at each strain rate was processed as follows. The elastic (linear) region was identified and the elastic

$$
\delta_{\text {fail }} \cong \frac{G_{I I}}{A_{T S C} \tau}
$$

Equation 1 Energy release rate for mode II [81] 
modulus was determined for each test. The end of the linear region (yield strength) was identified with the aid of Eq. 2 to determine when the plastic strain was greater than zero, using the modulus measured in the linear region of the response. The stress-strain response was then separated into elastic and plastic components (Eq. 2) and the resulting plastic strain versus stress data was fit using an empirical relationship between stress and strain(Eq. 3), which resulted in good quality fits and coefficients of determination (e.g. $r^{2}>0.95$ ). Finally, the plastic straintrue stress curves were averaged in a point-wise manner (Eq. 4) and the strains at failure were determined from averaging the failure strains for all of the tests, denoted by the counter $i$, at a particular strain rate, denoted by the counter $\mathrm{j}$ (Eq. 5). The same procedure was followed with the shear data, although in this case a polynomial curve type fit (Eq. 6) was more appropriate $\left(\mathrm{r}^{2}>0.90\right)$. It is worth noting that the described procedure was successful at preserving the integrity of the physical response in the material, which was not the case when all the available data for a single strain rate was curve fitted into a single expression.

Additionally, both models require values for modulus of elasticity in tension, in shear, density and Poisson's ratio. This information was ready available from the manufacturer and was verified in the experimental tests.

\section{CAE Modeling}

Single element simulations were used for a first level assessment of the constitutive models. In these simulations, the boundary conditions were implemented to obtain pure tension and pure shear (Fig. 2). In the second stage of this implementation, the actual test samples used in the experiments (TSHB and TLS) were simulated and subjected to the same loading as the experimental test conditions. The TLS used both CZM and continuum elements while the TSHB geometry used solid elements only (Fig. 2).

\section{Results}

\section{Experimental Test Results}

The tensile and shear test results showed that all three adhesive materials demonstrated significant strain rate sensitivity for both tension and shear modes of loading.

$$
\begin{gathered}
\varepsilon=\varepsilon_{\text {elas }}+\varepsilon_{\text {plas }} \\
\varepsilon_{\text {elas }}=\frac{\sigma}{E}
\end{gathered}
$$

Equation 2 Strain decomposition

$$
\sigma=A+B * e^{-C \varepsilon} \sinh ^{-1} \varepsilon+D
$$

Equation 3 Mathematical expression for curve fitting in tension

$$
\sigma_{a v g} \mid \dot{\varepsilon}_{j}=\frac{\sum_{1}^{n} \sigma_{i} \mid \dot{\varepsilon}_{j}}{n}
$$

Equation 4 Average curve for a particular strain rate $\dot{\varepsilon}_{J}$

$$
\varepsilon_{\text {fail }} \mid \dot{\varepsilon}_{j}=\frac{\sum_{1}^{n} \varepsilon_{\text {fail } i} \mid \dot{\varepsilon}_{j}}{n}
$$

Equation 5 Strain to failure in the average curve for a particular strain rate $\dot{\varepsilon}_{J}$

$$
\tau=A+B \gamma^{\frac{1}{2}}+C \gamma+\cdots+G \gamma^{7}
$$

Equation 6 Mathematical expression for curve fitting in shear

Figure 3 describes a data set from the testing showing strain dependency for one of the materials in tension as well as the relative strength between all three adhesives under quasi-static loading. The complete set of experimental results and material properties is provided in Online Appendix A. The dependency of material ultimate strength on strain rate for both tension and shear (Fig. 4) was quantified by fitting a log-linear curve (Table 1). In metallic materials, the strain rate effects are typically loglinear [82], but as can be seen in Table 1, for these three polymeric materials a non-linear fit may provide improved coefficients of determination. Non-linearity has been reported in the literature $[29,83,84]$ for polymers and epoxy adhesives. However, a linear fit was required for the cohesive constitutive model implementation. It was noted that variability in the data contributed to lower coefficients of determination and should be investigated in future studies. The EC-2214 and DP-460NS adhesives demonstrated the highest dependence on strain rate, based on the coefficient of the log-linear curve fit to the tensile strength data.

The shear response was different for each material as described by the stress-strain curves. In shear, the strain rate effects on the shear stress to failure were relatively small for DP-460NS while an increased sensitivity was noted in the curve fit for both EC-2214 and SA-9850 below strain rates of $50 \mathrm{~s}^{-1}$. The three materials also showed slight changes in modulus of elasticity with strain rate (Table A1; Fig. A1), where the modulus of elasticity was determined following the procedures described by the ASTM E-111-04 standard [85]. These changes in modulus were not incorporated in the numerical models but should be investigated in future studies. 
Undeformed geometry

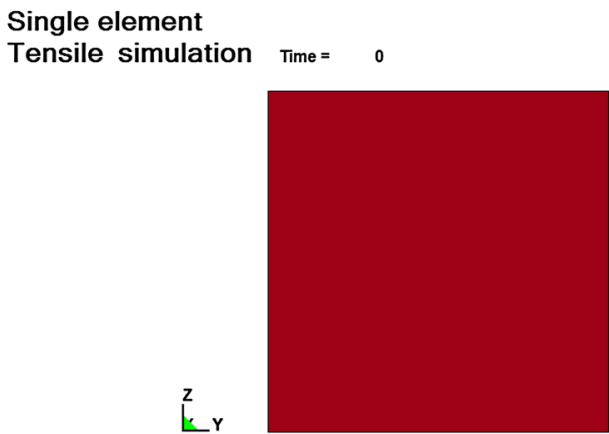

Single element Shear simulation
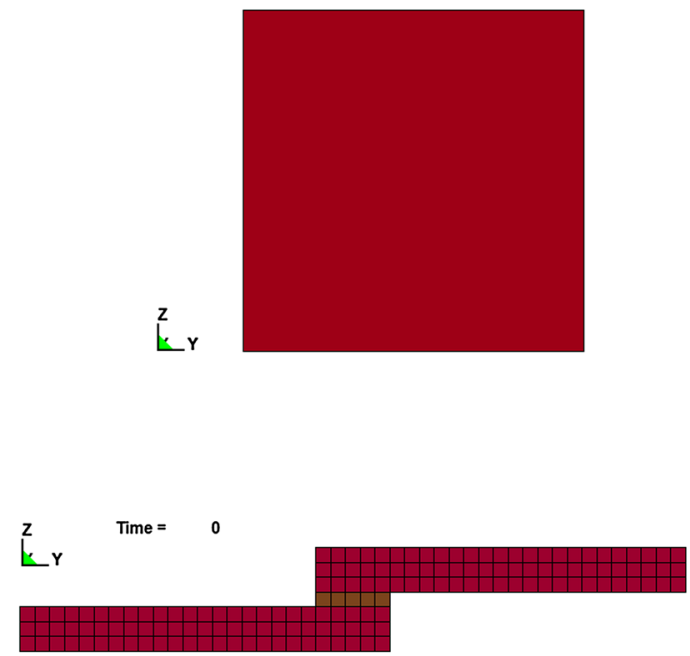

Time $=0$

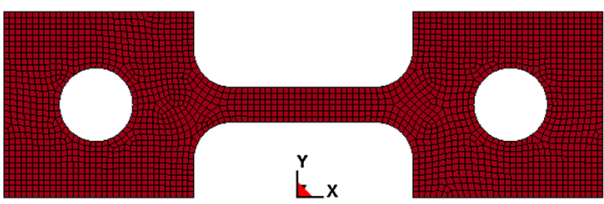

Deformed geometry
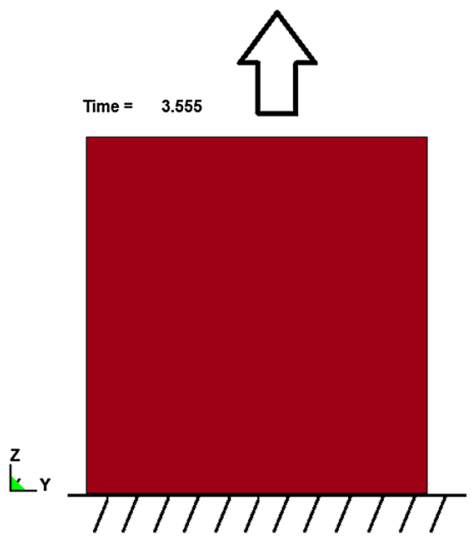

z.

Time $=0.5835$
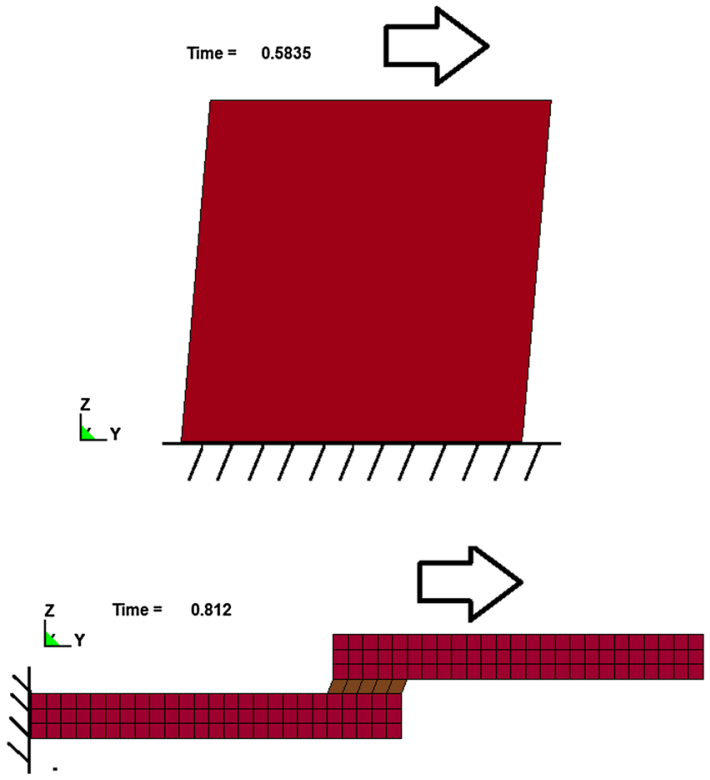

Time $=0.14$
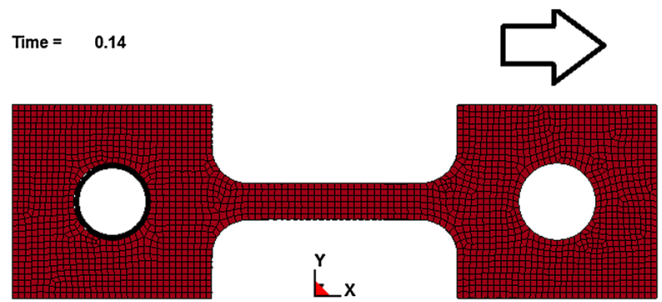

Fig. 2 Single element cases (top), TLS geometry (bottom left) and TSHB geometry (bottom right)

\section{CAE Implementation}

\section{Cohesive Zone Model}

The cohesive element formulation was implemented using the measured data from the tension and shear tests to describe the strain rate effects on the strength of the material (Table 1), also the modulus of elasticity and shear modulus used matched those published by the manufacturer and confirmed during the experimental testing (Table A2). The required fracture toughness values in Mode I and Mode II were obtained from the manufacturer 


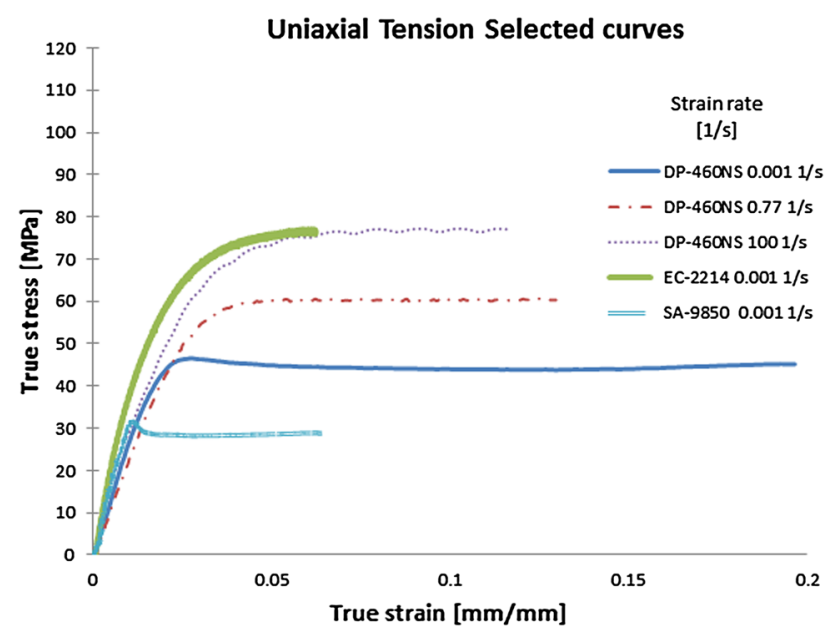

Fig. 3 Selected test results for tension in three structural adhesive materials

or the literature, or as previously explained any values not directly available were determined by matching the response of the cohesive model using a single element, to that of the measured data in the experiments. The complete sets of parameters for the cohesive models as implemented in a commercial finite element code (LS-DYNA) can be found in Tables B1 to B3 in Online Appendix B. The material properties were defined in the $\mathrm{mm}$-sec-tonneNewton unit system [51], commonly used in vehicle and structural models.

The response of the cohesive model using a single element was compared to the experimental results for the individual strain rates measured during testing (Fig. 5). In general, the CZM demonstrated good prediction of stress at failure. The results also showed excellent agreement in the elastic regime; individual results are illustrated in Online Appendix C (Figs. C1 to C6). The coefficient of determination $\left(r^{2}\right)$ value was calculated between the simulation response and the average stress-strain curve of the material for each of the strain rates tested. In general, there was good agreement between the models and the experimental data for both tension and shear loading; the calculated regression coefficients had a high value, typically around 0.8 under tension. The average value for shear loading was much lower $\left(r^{2}=0.59\right)$, attributed to the poor fit at higher strain rates between the average shear curve and the model response. At low strain rates, the calculated $r^{2}$ values were much higher $(\sim 0.9)$. Differences in the prediction of failure stress was $1.5 \%$ on average for tension and $2.39 \%$ for shear (Table 2) in the cohesive model; and for each individual case, the predicted stress value at failure was generally within one standard deviation of the experimental data average value. Tables C1 to C6 (Online Appendix C) contains all of the metrics for each of the simulations to calculate the averages presented in Table 2 for the cohesive model (stress at failure, standard deviation of experimental data, measured error, and $r^{2}$ ). In a few cases, the difference was higher, around $12 \%$, but this was due to the differences between the curve fit used to predict the strain rate effect on the stress and the average
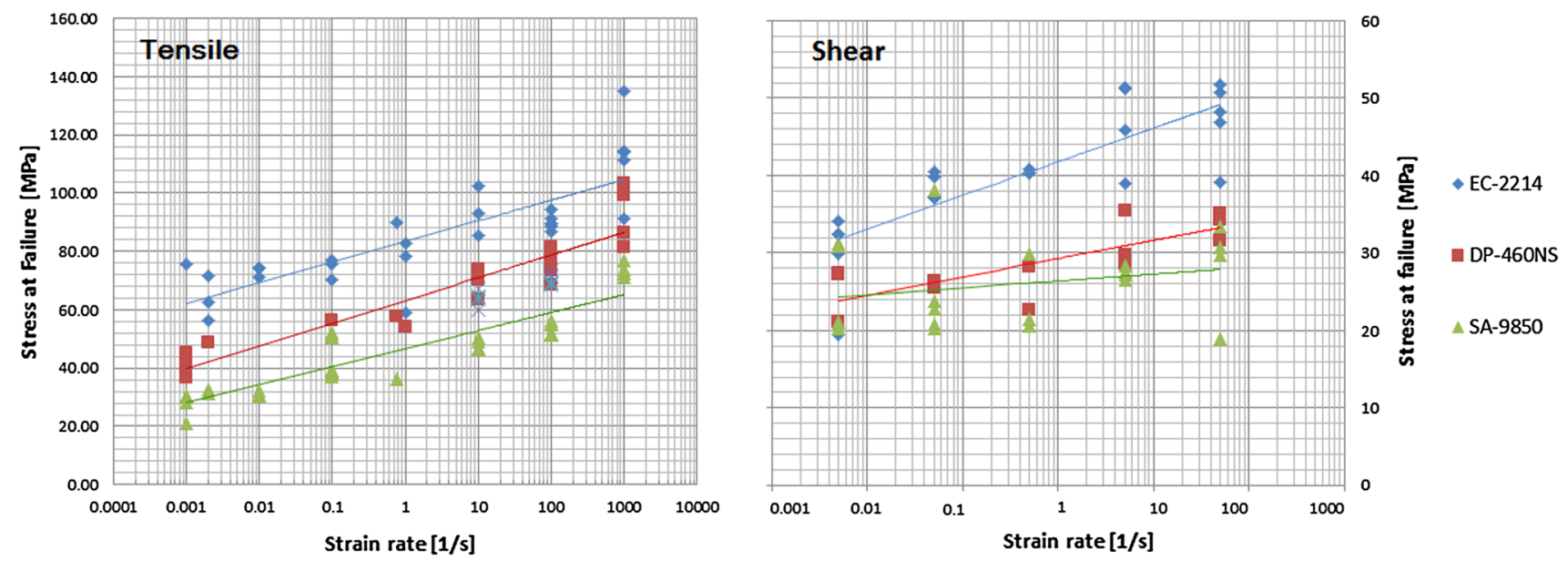

Fig. 4 Strain rate effects in the stress to failure for tensile and shear modes of loading

Table 1 Linear models for tensile and shear strength from Fig. 5

\begin{tabular}{lcccc}
\hline Material & Tensile data linear fit & $\mathrm{r}^{2}$ & Shear data linear fit & $\mathrm{r}^{2}$ \\
\hline EC-2214 & $3.06 \ln (\dot{\varepsilon})+83.46$ & 0.66 & $1.88 \ln (\dot{\varepsilon})+41.78$ & 0.68 \\
DP-460NS & $3.45 \ln (\dot{\varepsilon})+62.87$ & 0.88 & $1.02 \ln (\dot{\varepsilon})+29.27$ & 0.66 \\
SA-9850 & $2.68 \ln (\dot{\varepsilon})+46.75$ & 0.82 & $0.38 \ln (\dot{\varepsilon})+26.36$ & 0.06 \\
\hline
\end{tabular}



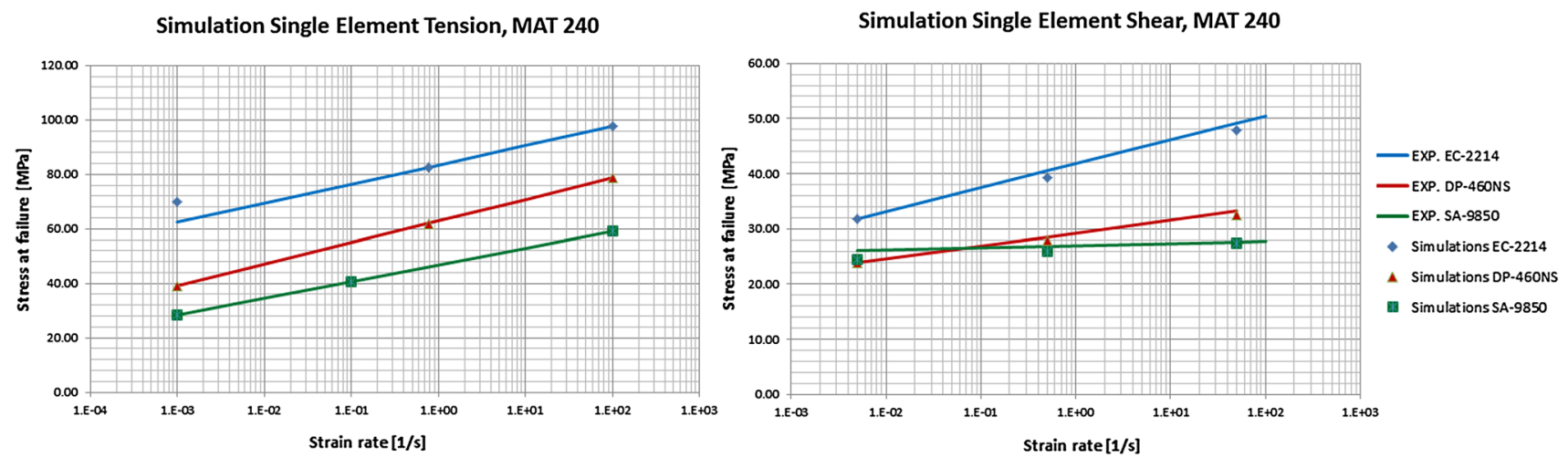

Fig. 5 Single element simulations results, CZM

Table 2 Model summary response metrics in single element simulations

\begin{tabular}{|c|c|c|c|c|c|}
\hline \multirow[t]{2}{*}{ Model } & \multirow[t]{2}{*}{ Adhesive } & \multicolumn{2}{|l|}{ Tensile response } & \multicolumn{2}{|l|}{ Shear response } \\
\hline & & Difference $(\%)$ & Average $\left(r^{2}\right)$ & Difference $(\%)$ & Average $\left(r^{2}\right)$ \\
\hline \multirow[t]{4}{*}{ Cohesive model } & EC-2214 & 4.08 & 0.70 & 1.90 & 0.53 \\
\hline & DP-460NS & 0.18 & 0.91 & 1.58 & 0.61 \\
\hline & SA-9850 & 0.00 & 0.83 & 3.68 & 0.64 \\
\hline & Overall & 1.42 & 0.81 & 2.39 & 0.59 \\
\hline \multirow[t]{4}{*}{ SAMP-1 model } & EC-2214 & 4.03 & 0.96 & 22.64 & 0.43 \\
\hline & DP-460NS & 0.61 & 0.99 & 14.61 & 0.55 \\
\hline & SA-9850 & 1.23 & 0.98 & 3.00 & 0.61 \\
\hline & Overall & 1.96 & 0.98 & 13.42 & 0.53 \\
\hline
\end{tabular}

stress value calculated from the available data points at those particular strain rates.

After the single element verification, the cohesive model was further investigated with the TLS geometry using rigid elements to represent the adherends. The response of the TLS models were identical to those of the single element simulations for DP-460NS, the same result was observed for the other two adhesives.

\section{Continuum Model}

The response of a continuum model using solid elements using the SAMP-1 constitutive model was evaluated using single element models and with simulations of the TLS and TSHB geometries. During the tensile single element simulations, all cases showed good agreement between model and experimental data although there was a small difference in the predicted plastic behavior, which increased with increasing strain rate. Even though in the implemented model the stress during the plastic deformation was slightly lower than the measure (Table 2; Fig. 6).

One specific assumption in the SAMP-1 model is that the material behaves linear elastic until yield, defined as the departure from linearity. Further, the model predicts the departure from the linear-elastic region of the material to occur at the strength corresponding to the lowest deformation rate provided (i.e. the first strength value of the plastic curve with lowest strain rate in the implementation), and did not initially follow the strength versus plastic strain data provided. In essence, the model uses the first yield from the lowest strain rate curve and then interpolates the plastic behavior using the provided curves at different deformation rates. This caused the differences noted in the transition region from elastic to plastic behavior.

In the shear loading cases, at low strain rates $(\sim 0.005$ $\mathrm{s}^{-1}$ ), the simulation response was in very good agreement with the actual elastic and plastic response from the test data $(<2 \%$ difference in maximum stress value, see Tables D1-D6 and Figures D1-D6 in Online Appendix D for each case results). In addition, the regression coefficients between the experimental data and the simulation were $>0.90$, but as the strain rate increased the difference in stress prediction increased up to $40 \%$ in some cases and the regression coefficient diminished in all cases $(<0.5)$. It was noted that the SAMP-1 model used the tensile strain rate sensitivity to scale both tension and shear loading response. In case of shear loading, the strain rate was calculated using the von Mises flow rule [45], linking the 

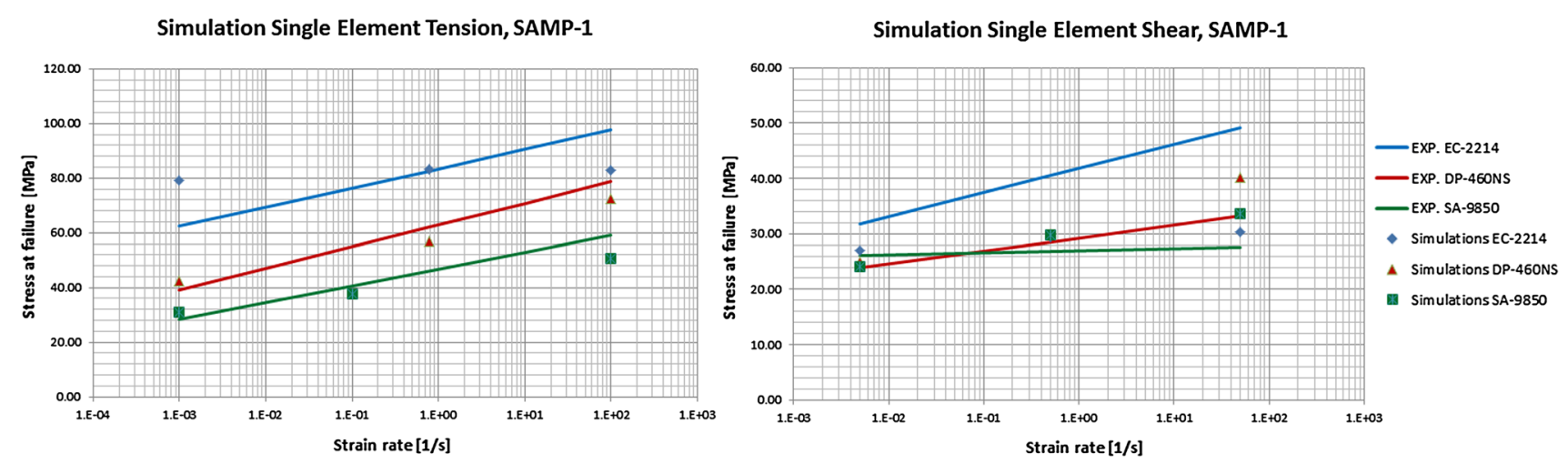

Fig. 6 SAMP-1 single element simulation results

Table 3 SAMP-1 simulations results for experimental geometries

\begin{tabular}{|c|c|c|c|c|c|c|c|}
\hline \multicolumn{4}{|c|}{ Tensile response } & \multicolumn{4}{|c|}{ Shear response } \\
\hline $\begin{array}{l}\text { Strain rate } \\
\left(\mathrm{s}^{-1}\right)\end{array}$ & $\begin{array}{l}\text { Stress difference } \\
(\%)\end{array}$ & $\begin{array}{l}\text { Strain to fail } \\
\text { difference }(\%)\end{array}$ & $\mathrm{r}^{2}$ & $\begin{array}{l}\text { Strain rate } \\
\left(\mathrm{s}^{-1}\right)\end{array}$ & $\begin{array}{l}\text { Stress difference } \\
(\%)\end{array}$ & $\begin{array}{l}\text { Strain to fail } \\
\text { difference }(\%)\end{array}$ & $r^{2}$ \\
\hline 0.001 & 3.93 & N/A & 0.97 & 0.005 & 4.53 & N/A & 0.89 \\
\hline 0.77 & 5.90 & 5.07 & 0.92 & 0.5 & 10.59 & N/A & 0.65 \\
\hline 100 & 2.36 & 17.07 & 0.93 & 50 & 15.37 & N/A & 0.05 \\
\hline
\end{tabular}

applied shear deformation to the provided uniaxial tension curves and hence did not accurately represent the strain rate effects for shear loading.

Further verification of the SAMP-1 model was pursued using simulations of the actual tested samples (i.e. tensile sample and thick adherend lap shear). In both cases a mesh convergence study was performed. Convergence was evaluated using the stress-strain response, element stress in a selected region, as well as the measured modulus of elasticity and shear modulus. From the study results it was determine that elements between 1.5 and $1 \mathrm{~mm}$ in characteristic length provide a converged solution for the tensile coupon while a smaller size $(0.25 \mathrm{~mm})$ was required for the TLS. The mesh size in the TLS model was constrained by the $1 \mathrm{~mm}$ adhesive bond used in the actual experiment, at least three elements across the joint thickness are recommended when using single integration point elements to capture any possible bending effects and the resulting stress gradient [39].

Figure 7 shows the stress-strain results for DP-460NS at three different strain rates $\left(0.001,0.77\right.$ and $\left.100 \mathrm{~s}^{-1}\right)$ for tension and rates of $0.005,0.5$ and $50 \mathrm{~s}^{-1}$ for shear. In all tension cases, the response of the SAMP-1 model was adequate, predicting properly the elastic response, the stress to failure as well as providing a good approximation to the transition between elastic and plastic behavior. The
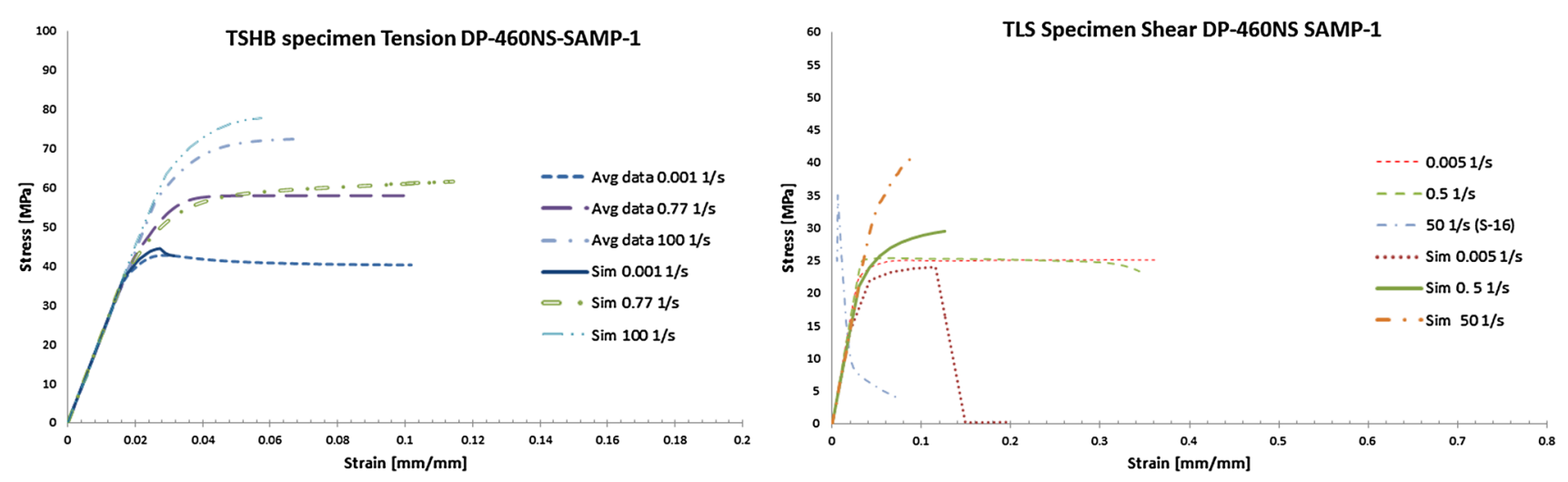

Fig. 7 Simulation results versus testing. Uniaxial tension (left), thick lap shear (right) 
implemented strain to failure criteria in the model was close to the specified parameters (below $13 \%$ error, Table 3). The TLS simulation presented the same type of limitations noticed in the single element simulations. That is, a good response at low strain rates, but departure from the measured behavior at higher strain rates. Simulations for SA-9850 and EC-2214 materials using the testing geometries was not pursued.

\section{Discussion}

\section{Experimental Testing}

Three different epoxy adhesive materials where tested under uniaxial tension using bulk samples and under shear loading using a thick lap shear sample geometry across a range of strain rates. The experimental results were of good quality but some challenges were identified during high strain rate testing. Under tensile loading using the split Hopkinson bar with the proposed geometry showed that the specimen was susceptible to non-equilibrium conditions. Even though the sample geometry is acceptable for testing metals, and impedance compatible aluminum bars were used; the sample gauge length was too long so that dynamic equilibrium was not achieved. Reducing the gauge length was not considered since previous testing has demonstrated the required reduction in length would not allow for uniform stresses to develop in the sample. The reported ultimate strength of the adhesive follows the trend from lower strain rates (Fig. 4). Efforts are underway to investigate modifications to the test using low impedance polymeric bars, pulse shaping techniques [86-88], or the atypical setup implemented by Rae [88].

Challenges were also noted with the shear testing at high strain rates, in this case high frequency oscillation were identified in the response at strain rates of $50 \mathrm{~s}^{-1}$ and higher, attributed to vibration in the test apparatus. To address this challenge, it is proposed that an alternate sample geometry (e.g. ASTM B831-14 [89]), be investigated. In general, most of the challenges identified were related to displacement or strain measurement while the measured load, particularly the maximum load, was found to be representative, since the differences between the calculated average stress at peak load and the shear data measured by the manufacturer (Table 4 ) are $<5 \%$ in difference for both DP and EC materials. The SA-9850 adhesive result from the manufacturer was lower, but the manufacturer data reported adherend failure, hence the actual adhesive property will be higher.

It is clear from the experimental data that all three materials were sensitive to strain rate for both tension and shear loading, exhibiting an increase in strength with increasing strain rate. To describe the effects of strain rate in the mechanical properties of these adhesives, the use of traditional log-linear models, as implemented for metals provided a reasonable fit to the data (Table 1). Previously, Nagai [29] demonstrated that the Cowper-Symonds model can be used to describe the effects on the compressive stress of DP-460 (a variant of DP-460NS as used in the current study), but over a limited range of strain rates $\left(\leq 100 \mathrm{~s}^{-1}\right)$.

A similar result was found for the data in this work. Out of the three materials tested, only DP-460NS show an improvement in the correlation coefficient when the strain rate range was narrowed. This is partially due to the scatter in the data, and may also support the possibility of a nonlinear relationship between strength and strain rate effects for this particular material. It is recommended that future testing consider non-linear models; however, this was not investigated in the current study since the constitutive models used could only account for linear variation in strength with the log of strain rate. Other authors have also highlighted the importance of considering non-linear models when selecting constitutive models to represent polymeric materials $[83,90]$.

Another important finding is that traditional yield criteria (e.g. Tresca or von Mises) that link tensile and shear properties are not applicable to the materials investigated in this study. For example, the shear response cannot be accurately predicted from the tensile data (Fig. 8), and the stress transformation (using von Mises theory) confirms that the strain rate effect is clearly not the same between the tensile and the shear data. As a result, complex concave yield surfaces may be required to properly capture and predict the yield behavior under load [73].More elaborate test apparatus (e.g. the modified Arcan [23, 91]) that can subject the samples to mixed mode loading, will be required to fully define the actual yield surface.
Table 4 TLS results versus manufacturer data

\begin{tabular}{lllc}
\hline Material & Manufacturer shear $(\mathrm{MPa})$ & TLS shear $(\mathrm{MPa})$ & Difference $(\%)$ \\
\hline EC-2214 & 31.02 (ASTM D-1002) & 31.82 & 2.51 \\
DP-460NS & 24.82 (ASTM D-1002) & 23.86 & 3.86 \\
SA-9850 & 19.00 (ISO 4587) & 24.34 & 21.93 \\
\hline
\end{tabular}



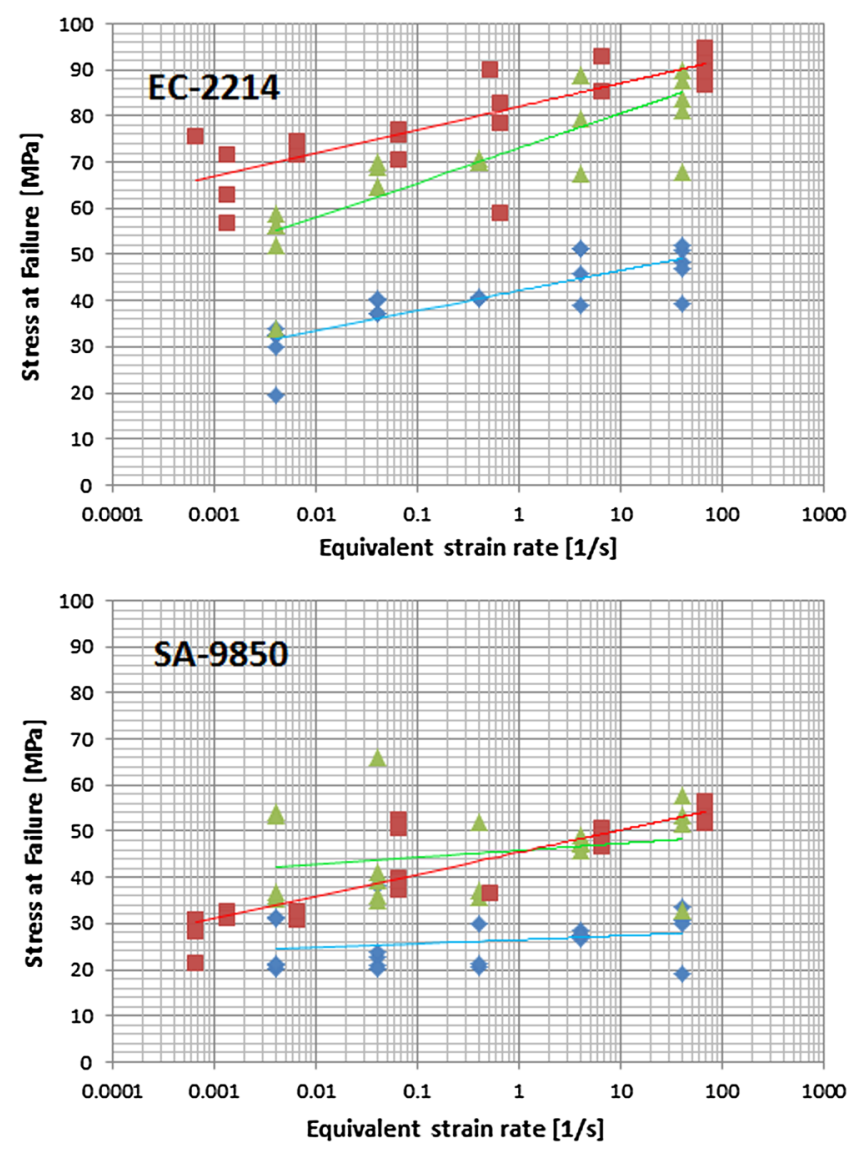

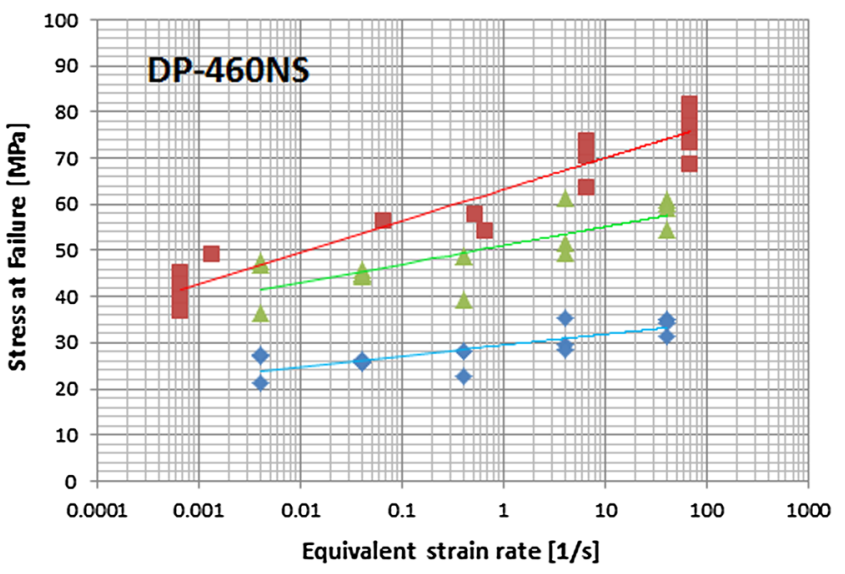

- Pure Shear experimental

$\triangle$ Equivalent Stress from Shear data

घ Uniaxial Tensile Data

Fig. 8 Equivalent tensile stress from shear stress against experimental tensile data

\section{CAE Implementation and Evaluation}

Two constitutive models, a cohesive zone model and a continuum approach using solid elements, were implemented to describe the measured mechanical behavior of three epoxy adhesives. Although both models were capable of describing the material response under the considered load conditions, some limitations were identified. From the experimental testing, it was clear that the strain rate effects may not follow a log-linear relationship across the entire strain rate range; however, in cases where the range of strain rates encountered was limited to only a few decades, a log-linear description of strain rate effects was found to be adequate.

Some authors have noted that $[36,37,92,93]$ the energy release rate for a polymer can be strain rate dependent or that the shape of the traction displacement curve changes with the strain rate. In particular, for this work the single element simulation for DP-460NS at higher strain rates other than quasi-static $\left(0.77\right.$ and $\left.100 \mathrm{~s}^{-1}\right)$ in tension demonstrated that it was not possible to obtain a match to the experimental response unless either the energy release rate was increased or the traction curve was modified.
Although the cohesive model considered in this study allows for energy release rate to depend on deformation rate, there was no experimental data to support incorporation of this in the present study. Although the individual response under tension and shear was very good, further investigation is needed to evaluate the model under mixed mode loading conditions.

In the case of the solid element formulation, the accuracy of the response was limited due to issues with strain rate effects implementation; in particular when loaded in pure shear at high strain rates or under mixed mode loading conditions. As noted in the model description, the shear response was scaled from the strain rate effects defined for tension, which is a limitation of the model. The strain rate dependency for these two modes of loading is not the same in the investigated materials (Fig. 8). This has been acknowledged as a limitation of the SAMP-1 [45] and further highlighted in the current study, particularly when considering intermediate to high strain rate effects in shear or under complex states of stress. It was also noted that similar challenges may be encountered for strain rate effects in compression based on the data measured by Nagai [29]. The Nagai data shows dependency of the 
modulus of elasticity and stress to failure with strain rate. If symmetric behavior between tension and compression stress to failure were to be assumed; the compressive data measured by Nagai [29, 52] overestimates the stress to failure in tension when compared against the measured data in this study, therefore the strain rate effects could also be decoupled between tension and compression. Although these tests concentrated on DP-460, a variation of DP$460 \mathrm{NS}$, similar effects may be expected for DP-460NS. Work by other researchers, Chen [87] and Farrokh [31]; has demonstrated asymmetric response in other epoxy materials between tension and compression for a wide range of strain rates. Considering the possible highly asymmetric nature of the yield surface based on the tensile and shear results, Tresca or von Mises yield theories are not applicable and models such as Coulomb-Mohr or DruckerPrager may be considered. Ideally, the models need to incorporate more flexibility in regards to load decoupling. Although the implemented strain to failure criteria in the model works well under pure tension, again issues with coupling affect the shear strain to failure, nevertheless the SAMP-1 model is the only available material model that can address some of the idiosyncrasies of polymeric materials and seems to be a good starting point for modeling structural adhesives using solid elements.

\section{Summary}

In this study, three different epoxy adhesives were mechanically tested under tension and shear modes of loading across a range of strain rates and the properties were implemented in two numerical formulations.

Tensile testing was undertaken using samples machined from bulk material and the stress-strain data demonstrated increasing failure strength, and decreasing failure strain, with increasing strain rate. The modulus of elasticity did not vary significantly with strain rate and was in good agreement with the reported values from the supplier. Variability in the quasi-static tests was low, but higher variability was noted for intermediate and high strain rate test data. Further, it was found that the samples were not in equilibrium for the high rate testing $\left(\sim 1000 \mathrm{~s}^{-1}\right)$. However, the measured strength values followed the log-linear relationship established at the lower strain rates and were therefore reported in this study. Further testing is recommended to measure the complete stress-strain response for high deformation rate loading. The adhesive shear response was measured using a thick adherend lap shear test, also demonstrating an increase in strength with increasing strain rate. The Mode I fracture toughness was previously measured using tapered double cantilever beam testing, while the Mode II energy release rate was determined from the shear test data. Future studies should include direct measurement of Mode II toughness and the dependence of toughness on deformation rate.

Implementation of the mechanical properties required average curves which were established for a given loading condition and deformation rate through an empirical curve fit followed by a point-wise average of the plastic strainstress curves. The effect of deformation rate was incorporated through a linear relationship between the material strength and the deformation rate. The strength values were adequately described with a log-linear relationship; typical coefficients of determination $\left(\mathrm{r}^{2}\right)$ were 0.8 for tension and 0.6 for shear.

Two different numerical implementations were considered in this study, and verified using single element simulations, followed by simulation of the actual test samples. A cohesive zone model using a cohesive element and the associated constitutive model, incorporating deformation rate effects provided a computationally efficient method of representing the adhesive joint dimensions, stiffness and failure response. It was noted, for the adhesives considered in this study, the incorporation of deformation rate effects was essential to accurately represent the material properties. In general, the cohesive model was able to reproduce the experimental test data for pure tension and pure shear for the toughened epoxy adhesives (DP-460NS and SA$9850)$, with $<8 \%$ difference on average. The cohesive zone model was able to reproduce the material strength of the non-toughened epoxy adhesive (EC-2214) but did not accurately reproduce the stress-strain response. Further investigations should consider evaluation of the cohesive model under mixed-mode loading.

Modeling was also undertaken using solid continuum elements and a constitutive model developed for polymeric materials. The solid elements were computationally more expensive, with the benefit of improved prediction of the stress conditions in the joint, when the mesh was sufficiently small ( $1 \mathrm{~mm}$ for the tensile test simulation, and $0.25 \mathrm{~mm}$ for the thick lap shear simulation). The SAMP-1 constitutive model was accurate for stress prediction and stress-strain response for all adhesive materials when pure tension at different strain rates was considered. Under shear loads at low strain rates, around the nominal strain rate of the provided data, the response was very close to the experimental data. One of the primary limitations of this model, the use of strain rate effects in tension to describe shear rate effects, was identified using the single element test cases. For all materials tested in this study, the effect of deformation rate on strength (i.e. log-linear slope) differed for tension and shear. It was shown that the model can produce large errors in the shear response at high strain rates, and this is also expected to affect results for mixed mode loading conditions. Additionally, it was shown that 
the shear stress could not be linked to the tensile stress by the use of traditional theories (e.g. von Mises). The three tested materials demonstrated the need to have at least both tensile and shear data available for proper modeling; it is possible that this is the general case for structural epoxies.

Numerical simulation of structural adhesives requires a constitutive model capable of calculating uncoupled strain rate effects for tension and shear loading, and deformation rate effects on strength must be considered if dynamic conditions are expected. The results of this study indicate that a cohesive zone model can provide an adequate representation of an adhesive joint for tensile and shear loading across a range of deformation rates.

Acknowledgments The authors would like to thank 3M Company, Initiative for Advanced Manufacturing Innovation and Automotive Partnerships Canada for financially supporting this research. The authors would like thank Compute Canada for providing the necessary computing resources and gratefully acknowledge Christopher Thom and Jeff Wemp for their assistance in adhesive material testing.

\section{References}

1. SuperLight Car program (2013)

2. Lightweight Vehicle Structure Conference (2009)

3. Symietz D (2005) Structural adhesive bonding: the most innovative joining technique for modern lightweight design, safety and modular concepts - progress report. SAE International

4. Kochan A (1996) Lotus: aluminium extrusions and adhesives. Assem Autom 16:19-21

5. Peroni L, Avalle M (2006) Experimental investigation of the energy absorption capability of bonded crash boxes $87: 445-454$

6. Peroni L, Avalle M, Belingardi G (2009) Comparison of the energy absorption capability of crash boxes assembled by spotweld and continuous joining techniques. Int $\mathrm{J}$ Impact Eng 36:498-511

7. Avalle M, Peroni L, Peroni M, Scattina A (2010) Bi-material joining for car body structures: experimental and numerical analysis. J Adhes 86:539-560

8. Fay PA, Suthurst GD (1990) Redesign of adhesively bonded box beam sections for improved impact performance. Int $\mathbf{J}$ Adhes Adhes 10:128-138

9. Belingardi G, Goglio L, Rossetto M (2005) Impact behaviour of bonded built-up beams: experimental results. Int J Adhes Adhes 25:173-180

10. Goglio L, Peroni L, Peroni M, Rossetto M (2008) High strain-rate compression and tension behaviour of an epoxy bi-component adhesive. Int J Adhes Adhes 28:329-339

11. ASTM (2015) Standard D1876-08, 2015, standard test method for peel resistance of adhesives (T-peel test). ASTM International, West Conshohocken

12. ASTM (2015) Standard D1002-10, 2015, Standard test method for aparent shear strength of single-lap-joint adhesively bonded metal specimens by tension loading (metal-to-metal) peel resistance of adhesives (T-peel test). West Conshohocken, ASTM

13. ASTM Website

14. Zhao X, Adams RD, Da Silva LFM (2011) Single lap joints with rounded adherend corners: experimental results and strength prediction. J Adhes Sci Technol 25:837-856
15. Zhao X, Adams RD, da Silva LFM (2010) A new method for the determination of bending moments in single lap joints. Int $\mathrm{J}$ Adhes Adhes 30:63-71

16. Adams RD, Harris JA (1987) The influence of local geometry on the strength of adhesive joints. Int J Adhes Adhes 7:69-80

17. 3M. 3M Scoth Weld, EC-2214 Technical data sheet

18. 3M. 3M Scoth Weld, DP-460NS Technical data sheet

19. Gilat A, Goldberg RK, Roberts GD (2007) Strain rate sensitivity of epoxy resin in tensile and shear loading. J Aerospace Eng 20:75-89

20. Kinloch AJ, Kodokian GA, Jamarani MB (1987) Impact properties of epoxy polymers. J Mater Sci 22:4111-4120

21. Sue HJ, Garcia-Meitin E, Orchard NA (1993) Toughening of epoxies via craze-like damage. J Polym Sci Part B 31:595-608

22. Jang BZ, Uhlmann DR, Vander Sande JB (1985) Rubber particle size dependence of crazing in Polypropylene. Polym Eng Sci 25:643-651

23. Choupani N (2008) Mixed-mode cohesive fracture of adhesive joints: experimental and numerical studies. Eng Fract Mech 75:4363-4382

24. Liu K, Piggott MR (1998) Fracture failure processes in polymers. I: mechanical tests and results. Polym Eng Sci 38:60-68

25. Mostovoy S, Ripling E, Bersch C (1971) Fracture toughness of adhesive joints. J Adhes 3:125-144

26. Kinloch AJ, Kodokian GKA, Jamarani MB (1987) Impact of properties of engineering adhesives. In: 2nd international conference of adhesion. Plastic \& Rubber Institute, p 1400

27. Cheng CM, Hiltner A, Baer E, Soskey P, Mylonakis SG (1994) Deformation of rubber-toughened polycarbonate-macroscale analysis of the damage zone. J Appl Polym Sci 52:177-193

28. Tang CY, Tsui CP, Shen W, Li CC, Peng LH (2000) Modelling of non-linear stress and strain behaviour of \HIPS with craze damage in tensile loading and unloading process. Polym Test 20:15

29. Nagai T, Iwamoto T, Sawa T, Sekiguchi Y, Kuramoto H, Uesugi $\mathrm{N}$ (2008) An experimental study on the impact deformation and the strain rate sensitivity in some structural adhesives. In: 9th AEPA 2008-Engineering plasticity and it's applications conference, pp 218-223

30. Yokoyama T, Nakai K (2006) Determination of impact tensile properties of structural epoxy adhesive butt joints using a hatshaped specimen. J de Phys IV 134:789-795

31. Farrokh B, Khan AS (2010) A strain rate dependent yield criterion for isotropic polymers: low to high rates of loading. Eur $\mathrm{J}$ Mech A/Solids 29:274-282

32. Mulliken AD, Boyce MC (2006) Mechanics of the rate-dependent elastic-plastic deformation of glassy polymers from low to high strain rates. Int J Solids Struct 43:1331-1356

33. Beguelin P, Barbezat M, Kausch HH (1991) Mechanical characterization of polymers and composites with a servohydraulic high-speed tensile tester. J de Phys 1:1867-1880

34. Georgiou I, Ivankovic A, Kinloch AJ, Tropsa V (2003) Rate dependent fracture behaviour of adhesively bonded joints. Eur Struct Integr Soc 32:317-328

35. Jamarani MB, Reed PE, Davies WR (1989) Fracture behaviour of UPVC thin tubes at high loading rates. Part 2. Validity of fracture toughness tests and the effects of rate. J Mater Sci 24:2917-2922

36. Khalil AA, Bayoumi MR (1991) Effect of loading rate on fracture toughness of bonded joints. Eng Fract Mech 39:1037-1043

37. Loo S, Zhang X, Ng H, Tee T, Mhaisalkar SG (2007) Impact of thermal, moisture, and mechanical loading conditions on interfacial fracture toughness of adhesively bonded joints. J Electron Mater 36:110-116

38. Selby K, Miller L (1975) Velocity dependent fracture toughness of epoxy-resins-reply. J Mater Sci 10:2003

39. LS-Dyna Aerospace working group (2013) Modeling guideline document: 163 
40. da Silva LFM, Ochsner A (2008) Modeling of adhesively bonded joints. Springer, Berlin

41. da Silva LFM (2012) Advances in numerical modelling of adhesive joints. Springer, Berlin

42. Morin D, Bourel B, Bennani B, Lauro F, Lesueur D (2013) A new cohesive element for structural bonding modelling under dynamic loading. Int J Impact Eng 53:94-105

43. Marzi S, Hesebeck O, Brede M, Kleiner F (2009) A rate-dependent, elasto-plastic cohesive zone mix-mode model for crash analysis of adhesively bonded joints. In: LS-Dyna European conference. Dynamore Gmbh

44. Marzi S, Hesebeck O, Brede M, Kleiner F (2009) A rate-dependent cohesive zone model for adhesively bonded joints loaded in mode i. J Adhes Sci Technol 23:881-898

45. Kolling S, Haufe A, Feucht M, Du Bois PA (2006) A constitutive formulation for polymers subjected to high strain rates. In: 9th international LS-Dyna users conference. Detroit, pp 15-55

46. Richardson G, Crocombe AD, Smith PA (1993) Comparison of two- and three-dimensional finite element analyses of adhesive joints. Int J Adhes Adhes 13:193-200

47. García JA, Chiminelli A, García B, Lizaranzu M, Jiménez MA (2011) Characterization and material model definition of toughened adhesives for finite element analysis. Int J Adhes Adhes 31:182-192

48. Castagnetti D, Dragoni E (2009) Standard finite element techniques for efficient stress analysis of adhesive joints. Int $\mathbf{J}$ Adhes Adhes 29:125-135

49. Wu G, Crocombe AD (1996) Simplified finite element modelling of structural adhesive joints. Comput Struct 61:385-391

50. van Hoof J (1999) Modelling of impact induced delamination in composite materials. Doctoral dissertation, Carleton University, Ottawa

51. Livermore software technology corporation (LSTC) (2007) LSDYNA Keyword user manual, Version 971. Livermore: LSTC

52. Iwamoto T, Nagai T, Sawa T (2010) Experimental and computational investigations on strain rate sensitivity and deformation behavior of bulk materials made of epoxy resin structural adhesive. Int J Solids Struct 47:175-185

53. Boyce MC, Parks DM, Argon AS (1988) Large inelastic deformation of glassy polymers. part I: rate dependent constitutive model. Mech Mater 7:15-33

54. Needleman A (1990) An analysis of tensile decohesion along an interface. J Mech Phys Solids 38:289-324

55. Yang QD, Thouless MD, Ward SM (1999) Numerical simulations of adhesively-bonded beams failing with extensive plastic deformation. J Mech Phys Solids 47:1337-1353

56. Mi Y, Crisfield MA, Davies GAO, Hellweg HB (1998) Progressive delamination using interface elements. J Compos Mater 32:1246-1272

57. Needleman A (2014) Some issues in cohesive surface modeling. Procedia IUTAM 10:221-246

58. Trimiño L (2012) Analysis and performance of adhesively bonded crush tube structures. M.Sc. Mech. Eng Thesis, University of Waterloo, Waterloo, Ontario, Canada

59. Boqaileh K (2015) Experimental testing and modelling of adhesively joined T-structures. M.Sc. Mech. Eng Thesis, University of Waterloo, Waterloo, Ontario, Canada

60. Belingardi G, Chiandussi G (2004) Stress flow in thin-walled box beams obtained by adhesive bonding joining technology. Int $\mathbf{J}$ Adhes Adhes 24:423-439

61. Cavalli MN, Thouless MD, Yang QD (2004) Cohesive-zone modeling of the deformation and fracture of weld-bonded joints. Weld J (Miami Fla) 83:133-S-139-S

62. 3M. 3M Scoth Weld, EC-2214 Safety data sheet

63. 3M. 3M Scoth Weld, DP-460NS Safety data sheet
64. Caruso Dailey MM, Trimiño L, Cronin D. 3M Scotch Weld (2012) SA-9850 Preliminary Technical data sheet, personal communication

65. Smerd R, Winkler S, Salisbury C, Worswick M, Lloyd D, Finn M (2006) High strain rate tensile testing of automotive aluminum alloy sheet. Int J Impact Eng 32:541-560

66. ASTM (2008) Standard, D638-08, 2008, standard test method for tensile properties of plastics. West Conshohocken, ASTM

67. Bardelcik A, Worswick MJ, Wells MA (2014) The influence of martensite, bainite and ferrite on the as-quenched constitutive response of simultaneously quenched and deformed boron steelexperiments and model. Mater Des 55:509-525

68. Sutton MA (2009) Image correlation for shape, motion and deformation measurements basic concepts, theory and applications. Springer, New York

69. Correlated solutions (2009) VIC-2D

70. ASTM (2012) Standard D5656-10, 2012, standard test method for thick adherend metal lap-shear joint for determination of the stress-strain behavior of adhesives in shear by tension loading. West Conshohocken, ASTM

71. Doghri I, Muller A, Taylor RL (1998) A general three-dimensional contact procedure for implicit finite element codes. Eng Comput (Swansea, Wales) 15:233-259

72. Greve L, Andrieux F (2007) Deformation and failure modelling of high strength adhesives for crash simulation. Int $\mathrm{J}$ Fract 143:143-160

73. Trimino LF, Cronin DS, Caruso Dailey MM (2015) Characterization of structural epoxy adhesives. In: SEM 2014 conference procedures. Springer, $\mathrm{p} 185$

74. Livermore software technology corporation (LSTC). LS-DYNA. 2014;1s971_d_R5.1.1

75. ASTM (2012) Standard, D3433-99, 2012, standard test method for fracture strength in cleavage of adhesives in bonded metal joints. West Conshohocken, ASTM

76. Sridharan S (2008) Delamination behaviour of composites, vol 726. Woodhead Pub, Cambridge

77. Blackman BRK, Kinloch AJ, Paraschi M (2003) On the mode ii loading of adhesive joints. Eur Struct Integr Soc 32:293-304

78. Kafkalidis MS, Thouless MD, Yang QD, Ward SM (2000) Deformation and fracture of adhesive layers constrained by plastically-deforming adherends. J Adhes Sci Technol 14:1593-1607

79. Tvergaard V, Hutchinson JW (1992) Relation between crack growth resistance and fracture process parameters in elasticplastic solids. J Mech Phys Solids 40:1377

80. Turon A, Davila CG, Camanho PP, Costa J (2007) An engineering solution for mesh size effects in the simulation of delamination using cohesive zone models. Eng Fract Mech 74:1665-1682

81. Livermore software technology corporation (LSTC) (2007) LSDYNA Keyword user manual, Material Models, Version 971. Livermore: LSTC

82. Blazynski TZ (1987) Materials at high strain rates. Elsevier Applied Science, London

83. Alves M (2000) Material constitutive law for large strains and strain rates. J Eng Mech 126:215-218

84. Morin D, Haugou G, Bennani B, Lauro F (2011) Experimental characterization of a toughened epoxy adhesive under a large range of strain rates. J Adhes Sci Technol 25:1581-1602

85. ASTM (2010) Standard, E11-04, 2010, standard test method for young's modulus, tangent modulus and chord modulus. West Conshohocken, ASTM

86. Chen W, Zhang B, Forrestal MJ (1999) A split Hopkinson bar technique for low-impedance materials. Exp Mech 39:81-85

87. Chen W, Lu F, Cheng M (2002) Tension and compression tests of two polymers under quasi-static and dynamic loading. Polym Test 21:113-121 
88. Rae PJ, Brown EN (2005) The properties of poly(tetrafluoroethylene) (PTFE) in tension. Polymer 46:8128-8140

89. ASTM (2014) Standard, B831-14, 2014, standard test method for shear testing of thin aluminum products. West Conshohocken, ASTM

90. Morin D, Haugou G, Bennani B, Lauro F (2010) Identification of a new failure criterion for toughened epoxy adhesive. Eng Fract Mech 77:3481-3500
91. Banks-Sills L, Arcan M, Bortman Y (1984) Mixed mode fracture specimen for mode II dominat deformation. Eng Fract Mech 20:145-157

92. Jamarani MB, Reed PE, Davies WR (1988) Fracture behaviour of UPVC thin tubes at high loading rates. J Mater Sci 23:4437-4444

93. Selby K, Miller L (1975) Fracture toughness and mechanicalbehavior of an epoxy-resin. J Mater Sci 10:12-24 